\title{
Using Boundary Objects to Co-Create Community Health and Water Knowledge with Community-Based Medical Anthropology and Indigenous Knowledge
}

\author{
Sarah Duignan, Tina Moffat, Dawn Martin-Hill
}

\begin{abstract}
AвSTRACT This article explores how Indigenous Knowledge and medical anthropology can co-construct community health knowledge through boundary work and the use of boundary objects. It will highlight how community-based participatory research (CBPR) in medical anthropology can help co-develop methods and strategies with Indigenous research partners to assess the human health impact of the First Nations water crisis. We draw on a case study of our community-based approach to health research with Six Nations of the Grand River First Nation community stakeholders and McMaster University researchers. We highlight how framing a co-constructed health survey as a boundary object can create dialogical space for Indigenous and western academic pedagogies and priorities. We also explore how this CBPR anthropology approach, informed by Indigenous Knowledge, allows for deeper foundations of culturally centered health to guide our work in identifying current and future community health needs concerning these ongoing water contamination and access issues. Through three health survey versions, priorities and research questions shifted and expanded to suit growing community health priorities. This led to collaborative action to communicate specific messages around water contamination and access across governance, community, and institutional boundaries. We demonstrate how our co-constructed approach and boundary work allows for the respectful and reciprocal development of these long-term research partnerships and works in solidarity with the Two-Row Wampum (Kaswentha) treaty established by the Haudenosaunee Nation and European settler nations.
\end{abstract}

KEYWORDS Indigenous knowledge; community-based methods; biocultural health; water governance and health; environmental determinants of health; co-creating knowledge

We have a great opportunity to learn from the past, reorient our relations, and build a relationship based on mutual respect and partnership in the sharing of responsibility in this land and natural world. To achieve this, we must transcend our individualistic motivations and move away from thinking in material terms.

- the late Chief Harvey Longboat (as cited in Blaser et al., 2001)

Indigenous health research has a painful legacy as rooted in western academic science. With significant health disparities between Indigenous and non-Indigenous populations in Canada, there has been growing attention towards building culturally sensitive Indigenous health assessments. The reliance on umbrella approaches to Indigenous health at times offers 
superficial tools and methodologies that focus on tailoring health approaches to be culturally sensitive or culturally competent (Wallerstein et al., 2019). These approaches look at Indigenous health through surface cultural structures, such as using specific food examples in dietary recalls, or culturally relevant symbols and imagery in health spaces (Resnicow et al., 1999). Often programs explore individual participant health or apply evidence-based approaches without seeking direction and leadership from the community to address their matters (Tremblay et al., 2019). In doing so, this reduces or ignores deeper cultural structures, such as community values, language, Local Knowledge, or the specific sociocultural and environmental challenges that a cultural community face.

In Canada, Indigenous Peoples' water supplies are in crisis due to poor water quality and quantity, lack of access to technology (such as real-time data and transparent standards for drinking water treatment), and skilled management systems. The ongoing legacy of colonialism has created and enforced structural barriers, and socioeconomic burdens for Indigenous Peoples across Canada that directly affect their daily access and quality of water and life. Inadequate infrastructure increases the health burden of these communities in ways not seen in mainstream Canadian society. The water crisis of Indigenous Peoples in Canada profoundly connects to the ongoing struggle to have Indigenous voices heard in the governance and decision-making processes. Bunch and colleagues (2011) suggest, "actions that address both biophysical and social environments have the potential to create a 'double dividend' that improves human health, while also promoting sustainable development (p. 8).”

While there is research exploring the physical health impacts of the longstanding Indigenous water crisis in Canada, the extent to which the water crisis impacts Indigenous health (as defined and understood by Indigenous communities) is less understood. In 2015, there were 105 long-term drinking water advisories issued in over 90 Indigenous communities, affecting more than 50,000 people across Canada (Indigenous Services Canada, 2019). Health inequities for Indigenous populations in Canada persist, and in many instances appear to be increasing with climate change, environmental contamination, and political tensions. The need to move beyond generic approaches to Indigenous health is critical for creating more effective and sustainable solutions to these human and environmental health issues. Indigenous wellness must center on land, language, community, cultural identity, and empowerment (Martin-Hill, 2009).

A growing body of work represents this shift away from former health intervention approaches towards co-creation of research that respectfully addresses and center communities' specific concerns and needs around health and wellness. Community-based participatory research (CBPR) approaches have been particularly useful ways to work with Indigenous communities in health research (Hoover, 2017; Trembley et al., 2019; Tobias et al., 2014; Wallerstein et al., 2019; Zurba et al., 2019). CBPR approaches involve "collective, reflective, and systematic inquiry in which researchers and community stakeholders engage as equal partners in all steps of the research process, with the goals of educating, improving practice, or bringing about social change" (Trembley et al., 2018, p. 2). This work is best understood as a philosophical approach and not just a methodology (Coombes et al., 2012). 


\section{Community-based Participatory Research with Six Nations of the Grand River First Nation}

This paper explores the ways that Indigenous Knowledge (IK) and medical anthropology can co-construct community health knowledge that is culturally centered using boundary objects within CBPR approaches. We draw on a case study of our community-based health research with Six Nations of the Grand River First Nation community stakeholders and McMaster University researchers. Our trans-disciplinary research project works with Six Nations of the Grand River Peoples in the lands known as Ontario to investigate a range of water challenges by co-creating knowledge and tools. Six Nations has endured generations of limited access to clean water and socioeconomic and human health hardships. The project is community-led, facilitating the sharing and integration of contemporary western science and Indigenous/ Local Knowledge in response to water quality threats.

To build respectful relationships within our research community of practice (RCoP) of Six Nations community stakeholders and university researchers, we use the emerging concept of boundary work to frame our co-construction of culturally centered health knowledge. Boundary work, and the use of boundary objects, are emerging concepts from health geography and other allied fields within design research and natural resource management (Zurba et al., 2019). Boundary work is "those acts and structures that create, maintain, and break down boundaries" (MacMynowski, 2007, p. 3). Boundary work involves and promotes collaborative action towards a particular issue and promotes mental flexibility about the roles or ways of engaging in the work (Wenger, 2000). Boundary objects are often integral to boundary work. Cash and Moser (2000) described boundary objects as "items that are valued on both sides of the boundary, and provide a site for cooperation, debate, evaluation, review, and [institutional] accountability" (p. 115). These objects are more tangible than boundary work itself.

As part of this boundary work, we co-created a community health survey and, in this paper, we discuss how the three versions of this health survey operate as boundary objects between sub-groups within our RCoP as our relationships and research priorities grew over 1.5 years. As the community health survey shifted through three distinct versions (or phases), community health priorities and the discussions around the survey led to collaborative action and communication about water contamination and access across community and institutional boundaries.

Through this boundary work, we also explore how CBPR approaches in medical anthropology informed by Indigenous Knowledge allow more culturally centered health practices to guide research by identifying current and future community health needs in relation to ongoing water contamination and access issues. We demonstrate how our co-constructed approach and boundary work allow for the respectful and reciprocal development of this long-term research partnership and works to be in solidarity with the Two-Row Wampum (Kaswentha) treaty established by the Haudenosaunee Nation and European settler nations.

We also outline important considerations and challenges experienced by Indigenous and western researchers during the first year of the project. We specifically look to the capacity that western researchers and anthropologists have to be reflexive of our positionality and biases, and how these approaches can help to decolonize the spaces and research collaborations 
we have with Indigenous Peoples in ways that are respectful of community knowledge and socioeconomic capacity.

\section{Co-Creation of Indigenous Water Quality Tools Project}

Co-Creation of Indigenous Water Quality Tools (CCIWQT) is our trans-disciplinary, community-led project, which works with Six Nations of the Grand River First Nation in southern Ontario, and with Lubicon Lake First Nation in northern Alberta. The project is funded through Global Water Futures (GWF), a seven-year research initiative aiming to find solutions that protect water quality and quantity across Canada and the cold regions of the world (GWF, 2020). GWF research projects provide governments, businesses, and communities with the risk management tools they need to tackle threats for Canada's water supply and quality, particularly in the face of dramatically increasing climate change risks (GWF, 2020).

The principal investigator for CCIWQT (DMH) is an associate professor in the Indigenous studies program and the anthropology department at McMaster University and is a member and resident of Six Nations. The large multi-disciplinary team of university researchers includes engineers and biologists, mental health professionals, obstetrician-gynecologist (OBGYNs), anthropologists, lawyers, philosophers, and Indigenous scholars, and Indigenous health care professionals from Six Nations Health Services and the Birthing Centre. Together, teams work in four separate but related teams: (1) community health; (2) ecosystem health; (3) water governance and Indigenous Knowledge; (4) and water quality monitoring. The research team also includes community navigators, research assistants, and project managers who are members and residents of Six Nations.

This article focuses on the collaborative health assessment work between CCIWQT's health research team and Six Nations stakeholders through three phases of developing a health survey. The community health team members were engaged with Six Nations community stakeholders and research partners to co-develop the community health assessments. The ecosystem health team members engaged in household water testing for organic and inorganic contaminants, briefly reported here as it relates to human health concerns and water use.

\section{Water Contamination Concerns at Six Nations of the Grand River}

Six Nations of the Grand River First Nation reserve is Canada's most populated First Nation community and geographically situated in the densely developed Greater Horseshoe region of Ontario (Baird et al., 2013). It is a large urban reserve occupying around 19 hectares of land. Despite having a water treatment plant within the community, drinking water quality remains a problem. Community leaders and collaborators have identified primary concerns around water: the quality of drinking water, the ecological integrity of water sources in and around the Six Nations lands, and the governance of these waters.

Drinking water treated by the water treatment plant is primarily sourced from the Grand River. However, according to an investigative piece in The Guardian in 2018, 91\% of homes are not connected to the community water treatment plant, and many do not have access to clean 
drinking water (Shimo, 2018). The direct impacts of water quality and access on community health are less documented for Six Nations but remain primary concerns for many in the community. The majority of residents at Six Nations rely on wells or cisterns (a large water tank or underground water reservoir). While this is a traditional form of water access, many of the wells were not properly built and have not been maintained. Due to pervasive concerns about water contamination, many households at Six Nations rely on purchasing bulk bottled water from the Six Nations water treatment plant or third-party water services and often transport this water to their homes themselves.

In 2003, a water quality survey of domestic wells in Six Nations found a widespread problem with E. coli contamination and total coliforms in groundwater (Baird et al., 2013). Concerns emerged about the treatment and distribution of drinking water, along with agricultural runoff, landfill contamination, and poor quality of well water (Baird et al., 2013). Six Nations has experienced enteric infections, and it is suspected many undocumented health problems are caused by contaminated drinking water sources (Baird et al., 2013). Despite the community initiating source water planning processes, the concerns over water quality, treatment, and autonomy are still significant for many community members. A 2010 survey conducted by Six Nations Elected Council (SNEC) found that $76 \%$ of residents used bottled water, rather than well or cistern water, as their primary drinking source (Baird et al., 2013). This was mostly due to their knowledge of how contaminated well water had been, and from previous reserve boil-water advisories.

In 2018, our project tested tap water samples from 75 households for pathogenic bacteria, metals, minerals, and organics. The tests revealed 22 of the household samples $(29 \%)$ were contaminated with E. coli, compared to $19 \%$ and $27 \%$ in similar studies carried out in 2003 and 2004, respectively (CCIWQT Report 2019; Neegan Burnside 2005). The water samples from the wells, cisterns, and taps of 78 households were also tested for 26 metals, minerals, and organics. Of this sample, 32 of the households (41\%) found to have elevated levels of at least one contaminant: chromium in one household $(1.5 \%)$, aluminum in 14 households $(21.5 \%)$, manganese in three households $(4.6 \%)$, arsenic in one household $(1.5 \%)$, mercury in 18 households (27.7\%), and uranium in one household (1.5\%) (CCIWQT Report, 2019).

\section{Community Health Assessment Survey}

Despite increasing concerns over water contamination from Six Nations community leaders and members, there remained uncertainty about water use at the household level, and connections between water use, contamination, and human health risks were unclear. As part of this broader project on water quality tools, the McMaster health research team (Tina Moffat, Sarah Duignan, Dawn Martin-Hill) and a community member and McMaster student assistant were requested by the Six Nations Health Services to assist in co-developing a community health assessment with Six Nations Health Services team.

This assessment included co-creating a health survey tool with Six Nations Health Services that accurately reflects Haudenosaunee values and wellness models that would provide an understanding of water use and security issues for households and the community a snapshot 
of holistic health. The health research team thought they could connect this survey assessment to the water contamination tests and analyze the relationship between water use and human health for residents now and for future generations.

Past community health assessments at Six Nations were carried out by external parties (often federally funded) and structured in ways that did not encompass Haudenosaunee health models. This resulted in decreased engagement rates and a decision to not participate in the First Nations Regional Health Survey (FNRHS) in 2017. While the use of IK is critical during every phase of the Co-Creation of Indigenous Water Quality Tools project, having IK guide the co-construction of health assessments, and framing them within CBPR philosophies allowed for the development of a health survey through three distinct phases: (1) A general and expansive community health survey based on previous federal Indigenous health surveys; (2) a short pilot water use and health survey that tackled the water-specific concerns emerging from the community and was integrated the ecosystem health team's water testing results; and finally (3) a holistic health and water survey centered in Haudenosaunee understandings of holistic health and more recent concerns about COVID-19.

In this study, we use three phases of health survey co-creation to discuss the collaborative relationships built between Six Nations and McMaster team members between January 2019 and August 2019. We explore how the survey helped to center Haudenosaunee-specific health models reflecting the interests, concerns, and assessment structures meaningful for Six Nations peoples, framing the survey as a boundary object co-constructing knowledge and helping navigate relationships between different stakeholders. Ultimately, having a boundary object created a space for fruitful dialogical discussions between local Haudenosaunee and western anthropological pedagogies. Figure 1 provides an outline of the main stakeholders working together through the health survey assessment.

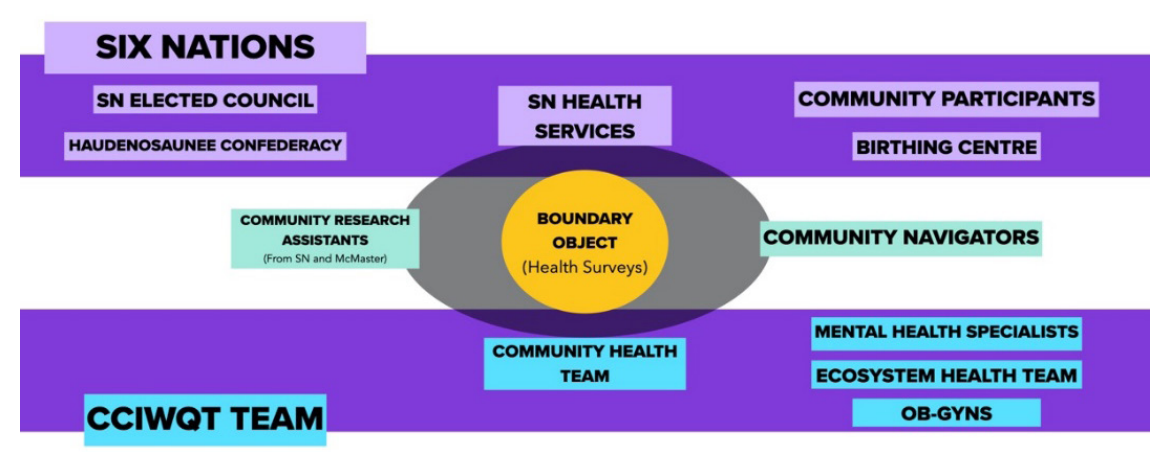

Figure 1. Key groups working in their rows to honour the Kaswentha, while meeting and building relationships at the boundaries through the health survey

\section{Understanding and Defining Community with Six Nations of the Grand River}

Understanding who constitutes community for Six Nations is best explored through the 
historical and current governance of the reserve. The Haudenosaunee Nations (People of the Longhouse) are sometimes referred to as the Iroquois or Six Nations and are one of the oldest Indigenous groups in North America. The Six Nations Confederacy was created hundreds of years ago by five linguistically related nations in the eastern Great Lakes region: the Mohawk, Oneida, Cayuga, Seneca, and Onondaga Nations. In the early $17^{\text {th }}$ century, the Tuscarora Nation joined as the sixth Nation in the Confederacy.

Often within Indigenous health research, the collaborating community stakeholders are solely at the level of First Nation Bands. In Canadian contexts, a First Nation band refers to "the collective of recognized members of a First Nation who have had lands set apart for their use by the Crown or are declared to be a band within the Indian Act" (Tobias et al., 2013, p. 132). The Indian Act of 1876 formalized restrictions for Indigenous Peoples within Canada, "including the dissolution of all existing traditional councils and the establishment of a federally approved elected-council system, as a means of controlling activity on reserves" (Monture, 2014, p. 69). As is the case with many First Nations communities, there are multiple forms of governance operating within Six Nations, which shapes not only community but land and water governance as well.

The Haudenosaunee Confederacy has been in place since time immemorial. Also known as the League of Nations, the five separate Nations agreed to live under the Great Law of Peace (or Kaianerekowa) provided by the Peacemaker (Monture, 2014). The symbol of the Confederacy is the longhouse, which was provided by the Peacemaker; it initially signified living together as families of the same house, but today is understood as a symbol that supports the traditional ways and values of the Haudenosaunee (Haudenosaunee Confederacy, 2020).

After the American Revolution, many of the Six Nations Peoples were displaced from traditional lands and moved to Upper Canada, where they were provided with the Haldimand Tract of land by the British Crown in and around the Grand River tract (Hill, 2017). However, much of this land was lost over time due to land sales, leases, and squatters (Haudenosaunee Confederacy, 2020). What land remained became Six Nations Indian Reserve Number 40 in 1842. The Haudenosaunee Confederacy have long maintained their sovereign nationhood (Monture, 2014).

The federally recognized Band Council also exists and operates within the reserve. This band council, Six Nations Elected Council (or SNEC), was enacted by the Canadian federal government in 1924 (Hill, 2017). Six Nations Elected Council (SNEC) represents the Band Council as defined by the Indian Act (Indian and Northern Affairs Canada, 2002). The community's water treatment plant operates under Public Works, which is within the jurisdiction of SNEC, as is Six Nations Health Services.

While these two governing bodies represent different community identities and relationships, it remains of great importance to develop reciprocal relationships with each governing body for this work. Conceptualizing community in referral only to SNEC or only to the Confederacy would be limiting, as the community is not homogenous, and Six Nations community members hold diverse spiritual, social, and political perspectives that impact their concerns and priorities. 


\section{Haudenosaunee Environmental and Political Philosophies}

As a project led by Six Nations of the Grand River peoples, we frame our work within several Haudenosaunee guiding principles, which will be briefly outlined here. Haudenosaunee environmental philosophies are contained with the Ohen:ton Karibwatebkwen, or Thanksgiving Address, the words they say before all else. This address acknowledges all parts of Creation and offers respect and gratitude to them for upholding their responsibilities (King, 2007). An important message for our work from the Ohen:ton Karihwatehkwen is that when the land is sick, the people become sick too (Haudenosaunee Environmental Task Force, 1992). For sickness in the community to be healed, sickness in the environment must first be addressed.

This teaching is a keystone to understanding how to center health assessments in Haudenosaunee culture. With federal health assessments that look at individual physical and mental health, such as the First Nations Regional Health Survey (FNRHS), these important connections between health and the environment are not addressed in relation to physical, social, and spiritual health issues. For Six Nations as a community, this means that past health assessments have not been anchored in how they understand health, and so important conditions and concerns around health may likely have been missed, misinterpreted, or underexplored.

The Kaswentha, or Two-Row Wampum was the first treaty between Europeans and Indigenous Nations on Anowarakowa Kawennote (Great Turtle Island, or North America), established between the Haudenosaunee and the Dutch settlers of eastern New York. It became the foundation of later treaties with France, Britain, and the United States and represents self-determination and a friendship treaty between these two nations. The Two Row Wampum belt is woven with white and purple beads or shells, depicting two boats on a river, with the purple rows representing the paths each boat makes as they travel down the river, one for the European ship, and the other for the Haudenosaunee canoe. While the boats travel alongside one another, their paths do not cross. Inside each boat is what defines it as a society: customs, laws, and ways of life. This symbolizes respect for autonomy for their own way of life and governance. The three white rows represent the river of life, and relationships based on skennen (peace), kariwiio (good mind), and kasastensera (strength) (Haudenosaunee Confederacy, 2020). The fringe on the belt indicates that the relationship is unending (Hill, 2017). Water represents both the river of life, but also the foundation on which the Kaswentha agreement is based.

Recognizing the role of water in the Kaswentha is important in understanding how settler colonialism has transformed the land and waterways. Through spatial reconfiguring, settlers transformed and re-territorialized waters, bodies, and beings (Schneider, 2013). In doing so, they have broken and tarnished the Kaswentha treaty: there have been over 400 years of dehumanizing assimilation, ongoing colonization, and violence on the part of white-settler society. Environmental destruction of the lands in and around Haudenosaunee territory is a form of this continued settler-colonial violence. Hallenbeck (2015) argues that centering research discussions around water "opens up a space for political and relational attention towards the bodies, being, stories, and histories that run through it" (p. 353). The contamination

Engaged Scholar Journal: Community-Engaged Research, Teaching, and Learning 
of the Grand River and surrounding waterways must be understood as directly connected to the dispossession of Haudenosaunee territory and subsequent health concerns.

To be in solidarity with the Kaswentha is to practice non-interference as a western researcher, to work in ways that are not exploitative. To decentre settler-colonial states, we need to work not only against power and control, but in ways that reimagine alternative institutions and relationships. Working with boundary objects helps to create spaces in which these difficult conversations may arise. Using a health and water use survey as a boundary object, discussions can emerge around the dispossession of Haudenosaunee territory, while decolonizing bodies of water like the Grand River in the process.

\section{Decolonizing Indigenous Research}

Decolonizing research has been a priority for Indigenous researchers, community members, and advocates for decades. Māori scholar Linda Tuhiwai Smith (2008) defines decolonization as "a process to undo harmful effects of colonization, including land theft, genocide, and assimilation" (p. 3). Decolonization is more of a praxis that matches theory with practice at every phase of research. Increasingly, we are seeing scholars implementing these approaches into their research, combatting western structures of power and knowledge. To do this, decolonization efforts might include involving elders, community members, and youth at all phases of research.

Language is a powerful tool in decolonization, so understanding key terminology and how it may be used (and how these uses may differ from project to project) is critical to building a foundation of respectful and appropriate work. There can be some confusion between indigenization and decolonization as terms. Indigenization often involves making a space "Indigenous" by including Indigenous peoples, as their presence brings a different perspective. This does not mean that these spaces are challenging white-settler frameworks. Decolonization attempts to challenge these systems of academic and western knowledge. Frequently, there are components of direct action taken to challenge injustices or systems that perpetuate the exclusion and/or assimilation of Indigenous peoples and their knowledges (Drawson, Toombs, \& Mushquash, 2017). Decolonization will look different from place to place and project to project.

Decolonization of research includes using IK as the framework and foundation for much research. IK and traditional medicine have been hard to define, as many understandings and descriptions from Indigenous peoples are rooted in deeply localized contexts (Martin-Hill, 2009).

While definitions vary, one of the most used definitions of IK frames it as the "complete knowledge system with its own concepts of epistemology, philosophy, and scientific and logical validity... which can only be understood by means of pedagogy traditionally employed by these people themselves" (Daes, 1994, p. 3).

IK approaches to health will vary based on the culture, language, and place of the communities collaborating on research. Donatuto and colleagues (2014) note, however, that IK concepts around wellbeing are "structured in content and internal logic and comprise practices 
and knowledge about connections between human beings, nature, and spiritual beings " (p.356). While the particular relationships between humans, nature, and spirit are understood and acted on differently across Indigenous cultures, these more profound responsibilities work within a network of sacred relationships that distinguishes IK from western perspectives on health and sustainable practices (Kealiikanakaoleohaililani \& Giardina, 2016). It is a participatory process and an experiential one - it is "not just about understanding relationships, it is the relationship with Creation" (McGregor, 2008, pp. 145-146).

While it is problematic to homogenize the cultures and belief systems of First Nations, water is one area where communities widely share similar attitudes and beliefs: water is life (Swain et al., 2006). For Six Nations Peoples, their teachings share that water is the first environment in our lives (in our mother's wombs). In IK, water degradation "directly impacts the people, permeating every aspect of their lives. It threatens their very survival" (McGregor, 2012, p. 10). Local relationships with water and their impact on community health are significant considerations that often get left out of First Nations health assessments. Understanding the histories and politics of water governance specific to each community is helpful in moving towards a more culturally centered assessment of community health.

\section{Decolonizing Community-based Participatory Research work within medical antbropology}

CBPR is seen by many Indigenous communities as a necessary standard if research is to continue with academic institutions, given the research abuses by academics in the past (Hoover, 2017). CBPR has been used across many research projects as a way of reducing health disparities for marginalized communities and ensuring health care programming that is culturally appropriate for Indigenous communities across a spectrum of health issues (Garwick \& Auger, 2003; Chrisman et al., 1999; Dignan et al., 2005; Strickland, 2006; Trembley et al., 2016; Zurba et al., 2019). Most importantly, CBPR builds a research foundation of a community's right to participate and a community's ability to refuse participation as central to ethical research with Indigenous communities (Zurba et al., 2019). Boundary work has been successfully incorporated into CBPR research with First Nations communities in Canada and Indigenous communities in Australia due to its ability to enhance equity and relationships within these research partnerships (Robinson \& Wallington, 2012; Zurba \& Berkes, 2013; Porter \& Barry, 2014; Maclean \& The Bana Yarralji Bubu Inc., 2015).

The traditional and cultural values of Six Nations Peoples are well aligned to work on co-developing a CBPR project and have used this approach with success in the past (Gordon et al., 2018). Their collective thinking, concern about how current decisions will impact future generations, and ability to approach gatherings and situations with kariwiio (a good mind) showcase their longstanding strength and autonomy as a Nation. The community has multiple decentralized community services, programs, and research projects, including their own research ethics board in relationship with SNEC, and other autonomous and consistent protocols through Confederacy to help create safer and more reciprocal research partnerships with academic institutions. For this phase of the research and beyond, we look to the Kaswentha as a reminder of how we can work together in our own rows to develop tools and programs. 


\section{Community Health Project Formation}

The health dimension of the Co-Creation team began discussions of community needs and concerns in January 2018 with Six Nations Health Services (Director Lori Davis Hill and portfolio team members). Ph.D. candidate Sarah Duignan began to work with Six Nations Health Services as a research assistant over a six-month period, compiling data from over twenty years of health assessments conducted with or by Six Nations Health Services to identify areas of health assessments that were consistently prioritized (or lacking) across multiple and varied household surveys and questionnaires. This allowed us to establish a baseline of what information was known about community health, and what (and who) was missing from the profile.

After realizing how much about community health was inconsistently assessed or not understood, Six Nations Health Services voiced interest in the development of a community health assessment survey that would eventually become an autonomous tool, to use now and for future community health assessments, independent of academics or other institutions such as the federal government. Connected to this was an existing gap in knowledge around how water contamination and water insecurity directly affects human health for Six Nations community members, and whether or not there were correlations between household water sample tests and health experiences. There had been previous work beginning to explore this through the 2010 Source Water Protection Survey through the Haudenosaunee Environmental Task Force, and these community stakeholders wanted to continue this exploration.

In co-constructing and using a survey, the degree of research fatigue experienced by community members must be considered. Six Nations Peoples are surrounded by four major universities, and their proximity to urban locations means they have an abundance of researchers interested in working with them. It is common to hear "We have been researched to death," which can feel like an understatement given Six Nations' size and geographical proximity to major research institutions in southern Ontario. This sentiment runs deeply across many First Nations communities, and feelings and experiences of research fatigue have been factored into ownership, control, access, and possession (OCAP) principles (First Nations Information Governance Centre, 2014).

Having an Indigenous scholar as principal investigator and a research team with diverse gendered and racialized identities certainly does matter and helps to make Indigenous researchers central in Indigenous research. For those of us on the project who are nonIndigenous, and speaking particularly to our anthropology backgrounds, it is important to be aware of the ugly history of anthropology rooted in racist science, and how we can actively work to unlearn biases through this collaborative work and in adherence to OCAP principles and local protocols and ethics (Marks, 2012; Smedley \& Smedley, 2005).

\section{Ethics Approval from Six Nations Research Ethics Board}

Ethics approval for the project-at-large was obtained in January 2018 from Six Nations Research Ethics Board, which represented the approval of Six Nations Elected Council. Verbal agreements and approval were expressed from the Haudenosaunee Confederacy in January of 
2018 as well. The umbrella approvals from SNEC and the Haudenosaunee Confederacy were necessary for the application for ethics from the McMaster REB. As this approval was granted for the large, interdisciplinary project, and did not provide the details of each phase and step of the project, institutional ethics boards found this more difficult to comprehend.

We expressed to the institutional REB that these approvals from the two governing bodies of Six Nations were granted as umbrella approvals only, due to the volunteer nature of the community REB and that many of those who worked on the REB were over-worked in multiple spaces. Coming to SNEC and the Confederacy with new formal addenda for each small part of the research project would be more work for them that would take them away from other important community work.

To work around these issues of capacity, the PI (DMH) and co-investigators have engaged in ongoing communication with both governing bodies of Six Nations. They share progress updates, and ask for assistance and insight on critical issues and concerns they may have around water and environmental health as they arise.

As the work continued to unfold, we worked out a memorandum of understanding with Six Nations Health Services, formally written and co-signed between our principal investigator and the director of health services. This established understandings and outlined key principles for the conduct of the research partnership involving community members and leaders. These were written and co-signed in September of 2018. Establishing these clear expectations and outcomes for both sides allowed for the development of ongoing open communication about each side's needs, wants, and abilities that they can bring to this work.

\section{Community Health Surveys as Boundary Objects}

The co-construction over two years (2018-2019) of a community health assessment served as the boundary object, or document, from which we were able to bring together parties within our research community of practice for the collective process and construction of a tool that would serve both Six Nations and McMaster collaborators' aims and goals.

There have been three primary versions of the community health survey over the two years, each operating as a boundary object between community and academic collaborators, and in different and overlapping ways. Table 1 outlines which stakeholders were involved at each stage in this boundary work. Figure 2 shows a timeline of the community health assessment survey development through the three versions. 
Table 1. Overview of survey types and stakeholders involved in development

\begin{tabular}{|l|l|l|}
\hline Survey Version & \multicolumn{1}{|c|}{ Stakeholders Involved } & \multicolumn{1}{c|}{ Use of Survey } \\
\hline $\begin{array}{l}\text { 1: General } \\
\text { Longform } \\
\text { Wealth and }\end{array}$ & $\begin{array}{l}\text { McMaster: community health } \\
\text { team, mental health team } \\
\text { Six Nations: Six Nations } \\
\text { Health Services stakeholders, } \\
\text { SNEC, Confederacy }\end{array}$ & $\begin{array}{l}\text { Broad: focused on similar } \\
\text { assessments as FNRH but to use } \\
\text { autonomously and comparatively; } \\
\text { physical, mental health focus }\end{array}$ \\
\hline $\begin{array}{l}\text { 2: Water use and } \\
\text { bealth pilot }\end{array}$ & $\begin{array}{l}\text { McMaster: Community health } \\
\text { team, ecosystem health team } \\
\text { Six Nations: SNEC, } \\
\text { Confederacy, community } \\
\text { members }\end{array}$ & $\begin{array}{l}\text { Specifically targeted to households } \\
\text { whose water was tested for } \\
\text { contaminants to assess water use, } \\
\text { self-reported health, and better } \\
\text { understand role of water in health } \\
\text { concerns }\end{array}$ \\
\hline $\begin{array}{l}\text { 3: Culturally } \\
\text { centered bealth, } \\
\text { wellbeing, and } \\
\text { water survey }\end{array}$ & $\begin{array}{l}\text { McMaster: community health } \\
\text { team, mental health team, } \\
\text { ecosystem health team, OB- } \\
\text { GYNs } \\
\text { Six Nations: SNEC, Six } \\
\text { Nations Health Services, the } \\
\text { Birthing Centre, dietician, } \\
\text { Grandmother's Council, } \\
\text { community fishers and hunters }\end{array}$ & $\begin{array}{l}\text { Informed by pilot (SV2) and } \\
\text { ongoing feedback, co-constructed } \\
\text { health and water use survey } \\
\text { grounded in Haudenosaunee values }\end{array}$ \\
\end{tabular}
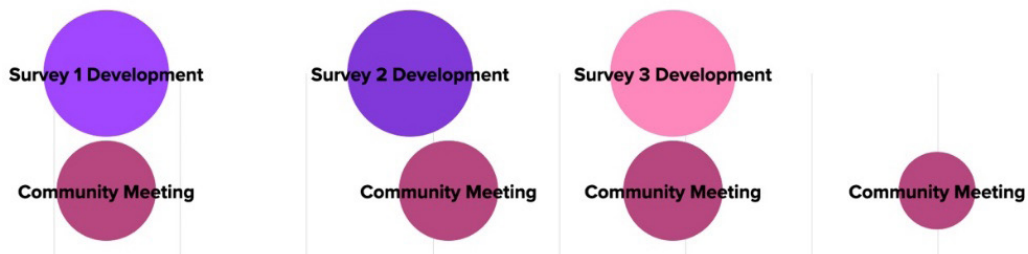

2017 December

2018 June

2019 January

2019 August

2020 March

Figure 2. Timeline of community health survey development 


\section{Survey Version 1: A General Longform Health Survey}

The health survey version 1 (SV1) was developed over the summer of 2018 in collaboration with Six Nations Health Centre. SV1 was a lengthy 30-page survey that reflected Haudenosaunee wellness models while containing measurements of individual health that would be comparable with other First Nations Peoples' health outcomes, as requested by Health Services. It was also developed to be eventually used as an autonomous tool, separate from federal and provincial funding bodies, and had community appropriate snowballing sampling strategies.

Conversations arose during the co-construction of questions in meetings between Six Nations Health Services employees and McMaster researchers around the importance of understanding community traumas. Many Health Services employees wanted trauma-informed questions addressing personal and collective intergenerational and historical trauma. These were important to understand better physical and mental health trends (around chronic pain and mental illness in particular). These meetings became spaces where community members within the RCoP vocalized and engaged in difficult and often personal topics. Structuring the health survey to reflect these diverse forms of collective and individual trauma, which are often bypassed by white-settler approaches to health, helped to challenge traditional power structures and allowed for vulnerable exchanges between stakeholders.

This became one of the first steps in the co-creation process, where power was redistributed in the development of a health survey. As surveys administered within Six Nations in the past often failed to consider and hold community values, re-centering this survey allowed for the knowledge, values, and belief systems held by community stakeholders to be prioritized. The survey as a boundary object helped navigate the boundaries of work between Six Nations Elected Council, Health Services, and McMaster researchers; at survey construction meetings within-community dialogues arose from crucial questions the health survey brought up.

Three main concerns arose: (1) prioritizing health beyond the physical, individual level; (2) engaging community sub-groups who were often left out; and (3) effective and accessible ways to conduct and launch the survey. These were often interrelated concerns, as the generic approach to federal surveys operated through random sampling of households. This meant that the survey would target the person in the home holding the most knowledge of the family (often a female-identifying person) but would only ask questions specific to their person. Additionally, these surveys were administered as pen-and-paper to be mailed back to the survey collectors, which is a tedious and inaccessible method for many, particularly younger generations. The result was consistently having men and youth under-represented in survey data, as well as biases in what health concerns were prioritized. Finally, by centering the survey in the Six Nations Health Services we were attempting to decolonize the research process by questioning who has the capacity to launch the survey, how is the survey conducted, and data storage. While these latter points are still being worked out with the upcoming survey version 3 (SV3), the primary goal of creating these surveys is to eventually have a consistent community health assessment for future use that can be stored in SNHS, and conducted with aid from community navigators, community research assistants (RAs), and McMaster researchers.

Engaged Scholar Journal: Community-Engaged Research, Teaching, and Learning 
McMaster stakeholders also engaged in discussion between separate co-teams within the project. The mental and community health researchers were able to hold conversations around merging our health questions as per the recommendations of Health Services employee recommendations and experiences. Further, it helped non-Indigenous researchers more strongly understand the diversity of perspectives and priorities within different Six Nations Health Services operations and allowed us all better insight into just how big of an undertaking it would be to co-create a tool that was useful and appropriate for the community and useful for academic forms of research and publication. The long form survey was paused in December 2018, due to increasingly limited capacities of some relevant SNHS stakeholders. While the long form survey was paused, the Co-Creation of Indigenous Water Quality Tools project focused on how to address the specific results of the household water quality tests with other community stakeholders.

\section{Survey Version 2: The Piloted Water Use and Health and Water Use Survey}

With the realization that household water testing required a focused survey for the specific households engaged in water testing, survey version 2 (SV2) was shortened to 10 pages and more directly connected water quality, use, security, and perspectives on water governance with measured household-level health experiences. This was developed in January of 2019, with ethics approval obtained from McMaster Research Ethics Board in February 2019 and brought to Six Nations Band Council and Confederacy on two separate retreat days in March 2019 and met with approval. As explained above, the McMaster researchers in the ecosystem health assessment dimension of the CCIWQT project tested the tap, well, and cistern water of 75 households (selected through snowball sampling) for biological and heavy metal contamination. Those who participated in their water testing in the summer of 2018 were invited to complete the SV2 during a household visit.

These retreats and meetings further allowed for community partners to express their interest in helping support the dissemination of the health survey, as it relates to the water testing results that both SNEC and Haudenosaunee Confederacy were made aware of during these meetings. Going through the survey questions prompted discussions around specific water concerns for SNEC members, and with Confederacy it inspired discussions of teachings around water's role in the community.

SV2 was launched in April 2019, and then operated as a boundary object between the research team and community members as well. A team of research assistants (RAs) that were both Indigenous and non-Indigenous worked within the community making household visits for those who consented to participate in the survey. The survey acted as a jumping-off point for more discussion in many instances. Questions on the survey prompted discussion between community participants and RAs: personal and family health experiences were shared on both sides, perspectives around water's role in health and wellbeing arose, and many concerns around water contamination were prompted in working through the survey.

For many community members who participated in the survey expressed tremendous dissatisfaction with water services and governance in the community. Even those who were 
financially comfortable enough to purchase bottled drinking water believed that there was much work to be done on improving the health of the Grand River and its offshoots: if they could not use the water and lands around it the same way generations before could, could the community really be healthy? Indigenous RAs spoke on a more personal level with household and community members and were able to put a face to the research, which was important for building long standing relationships. Further, it gave space for all of us working at our boundaries to better understand each other: for the medical anthropologists, it was a time to listen actively and bring the participants' values and perspectives back to the table when we met with other McMaster researchers on the project and the community stakeholders at further meetings.

\section{Survey Version 3: Culturally Centered Haudenosaunee Health and Wellbeing Survey}

The third version of the survey (SV3) was adapted from SV1 and was co-constructed over the summer of 2019 during multiple face to face and digital roundtables with representatives from Six Nations Health Services, the Birthing Centre (Tsi Non:we Ionnakeratstha/Ona:grahsta'), a McMaster OB-GYN with longstanding research relationships with the Birthing Centre, the CWIQT mental health and wellness and community health teams, a registered dietitian, community fishers and hunters. Additionally, the survey was reviewed by a Grandmother's Council through meetings with the mental health team.

This process involved several meetings between interested stakeholders to go through an array of past health surveys (an ongoing Birthing Centre study, examples from the mental health team, and the pilot SV2) to work towards a co-constructed longform survey that represented Haudenosaunee health values. These meetings opened up room for much deeper discussions, as our relationships with each other had grown over the year and a half. Many of us were mothers, and informal discussions about our children then led to much more nuanced discussions of maternal-specific health risks related to water quality for Six Nations residents (e.g. contaminated water and sitz baths postpartum, or lack of access to clean water for traditional medicine making). These were questions none of us had previously considered assessing through research. However, the space provided through these surveycentric meetings allowed us all to draw more reliable culturally-centered connections between water and health for the Six Nations community and to think about more representation from the more vulnerable community members.

Meetings with Faith Keepers and Clan Mothers of the Confederacy helped the survey take a more Haudenosaunee shape. Questions were framed in ways that were open enough for all Six Nations community members (regardless of spiritual or political views), but still reflected fundamental traditional teachings and IK. This was, at times, a more challenging element of co-constructing questions, given the particular skills and tools that academics were used to working with for studies not always being in line with the ways Six Nations collaborators wanted the questions constructed.

Working on questions around mental health at times proved challenging, as most mental health assessments are formatted within validated Likert scale formats (such as positive and 
negative affect scales, and resiliency scales) or with checklists (such as for post-traumatic stress disorder and trauma-related altered states of consciousness). While validation of scales is useful if the goal is to compare a research study's results to the results of other study populations, this is not a priority for the SNHS. Cross-comparisons are not useful in any immediate sense for the Six Nations community, especially given that the psychosocial burdens around mental health for Six Nations Peoples will be very different from other communities' given their unique relationships to water and land.

There have been numerous surveys exploring western-centric mental health assessments over the years at SNHS, so health care providers were more interested in prioritizing more predominant gaps in knowledge to help frame future programs and policies around mental health and environmental connections. Rather than use these generic validated scales, the group determined it would be best to explore the relationship between one's mental or social health and water quality by asking Likert scale questions such as "I seek out opportunities to spend time around natural sources of water" or "I feel better when I am around natural sources of water." These questions then lead to more specific questions around water-related health practices, such as picking traditional medicines or canoeing and kayaking on the Grand River. These questions were much more relatable for the community than generic mental health questions. They also create a space allowing for more open discussion afterwards about traditional medicine use and access with future participants, because traditional teachings are infused across the survey.

\section{Towards a Culturally-Centred Health Assessment Document}

By framing the health surveys as boundary objects that reflect the boundary work between Six Nations and McMaster team members, we were able to move towards a more culturally centered approach to health assessments that are reflective of CBPR principles. The ongoing development allowed for reflection on the relationships and research goals for all members of the RCoP. Each phase incorporated more communal learnings into the research partnership, and more space for Six Nations community members to participate in the research process.

For many marginalized populations, they have dynamic collective consciousnesses rooted in land and language but must respond to oppressive mainstream sociopolitical structures that impact their health (Airhihenbuwa \& Liburd, 2006). Rooting this health assessment in relationships to land, language, and community identities speaks to more dynamic and deeper understandings of health and the social, cultural, and political barriers that Six Nations Peoples face. A health assessment based on traditional teachings around water and land is also a step towards more empowerment and autonomy in their community health research.

As stated earlier, a foundational teaching within the Oben:ton Karibwatebkwen is that when the land is sick, the people become sick, too. Rather than researching just how Six Nations Peoples are becoming sick and isolating these experiences from the contamination and degradation of their lands, we are working towards building tools that connect these elements more holistically. This creates tools that are more engaging and empowering, as community members see their values and experiences reflected in the structure of questions. In the case 
of the smaller community health and water use pilot survey, the survey became a springboard for conversations between participants and the community RAs. They could highlight their own experiences, share important lessons, and know that these conversations will be honoured in the ways the work is shared back with community stakeholders and at events in the future.

For us, as medical anthropologists, it has been an ongoing reflection and assessment of power in health research. This means that we mobilize our power and skillsets as researchers to support broader partnerships within the community as research continues, and recognize the specific skills, interests, and concerns that all parties bring to the table. We are able to reflect upon these through how the survey versions adapted as we brought more parties into our research community of practice. Rather than build longer and longer surveys where community and research needs were roughly patched together without considering how to make them more cohesive, we were able to structurally change the documents so that the foundation was rooted in community IK. The lives and needs of Six Nations Peoples are the core that drives this research forwards, and these engage with non-Indigenous academic lives and approaches along the way.

\section{Community-based Participatory Research as Philosophical Stance in Medical Anthropology}

As medical anthropologists working within CBPR approaches, community partnerships are essential sites for co-constructed meaning-making. To honour local IK here means reflecting on our power and privileges as researchers. Tobias et al. (2013) argue that for social scientists working within CBPR initiatives with diverse Indigenous communities, this work "should ideally pursue a set of common objectives: to equalize power differences within the research process; to build trust between the researchers and community; and to foster a sense of ownership tied to generating momentum toward social change” (p. 132).

For a genuinely respectful co-creation partnership, it should also centre decolonizing methods. Dakota scholar Kim TallBear (2013) argues that "rather than integrating community priorities with academic priorities, changing and expanding both in the process, decolonizing methods begin and end with the standpoint of Indigenous lives, needs, and desires, engaging with academic lives, approaches, and priorities along the way" (p.20). For non-Indigenous researchers, this sets new expectations for how we approach our work: we are expected to seek and incorporate community suggestions and directions for research, while being open to learning and accommodating changes to research trajectories and timelines along the way (Hoover, 2017).

The literature on CBPR approaches within medical anthropology is scant, though there is some research on participatory action research (PAR) with similar lenses. The medical anthropology research that does explore CBPR usually discusses it relative to graduate studies education and training opportunities with marginalized communities, and not specifically with Indigenous Peoples (Jessee et al., 2015; Sheehan et al., 2014). There is work within archaeological research that utilizes CBPR, though CBPR is often used as a tool and not as a decolonizing philosophical approach (Atalay, 2007; Hollowell \& Nicholas, 2009; Nelson, 2017; Gonzalez et al., 2018; Alvarez, Larrain \& McCall, 2019). Atalay (2019) argues that while CBPR within 
archaeology is growing, the need for more decolonized models and collaborative, sustainable systems are needed for true systemic change within the discipline.

Watson (2019) argues that with the increased interest in PAR and the 'action turn' in anthropology, it is beneficial to repurpose the language of PAR to facilitate more nuanced discussions of what PAR (and CBPR) can be within anthropology. By using CBPR as an approach to research and relationship-building with community stakeholders, and not just as a tool for assessing health, medical anthropologists can engage in deeper understandings of these relationships between health, community, and land. Cochran et al. (2008) note that what may be most important in CBPR projects is how researchers acquire knowledge working with Indigenous communities, as these methods "may be as critical for eliminating health disparities as the actual knowledge that is gained about a particular health problem." (p.22). The process of respectful relationship building helps challenge power hierarchies shaped by past academic abuses and is integral to mending and co-creating health knowledge.

Medical anthropology has moved away from biomedical approaches of health towards a critical medical anthropology (CMA) over the years. Recent research is more reflexive of biomedical practices, moving away from viewing biomedicine (and western health systems) as an "objective adjudicator of truth and fact that is somehow removed from cultural influences" (Newnham et al., 2016, p. 2). Work within CMA takes a political ecology of health lens, where economic, political, social influences that shape locally contextualized health and disease outcomes - and particularly dimensions that shape health inequalities (Jackson \& Neely, 2015; King, 2010; Mayer, 1996; Richmond et al., 2005). Still, there remains space to improve medical anthropological approaches through decolonization and CBPR approaches.

A crucial difference between CBPR and CMA approaches is the shape that fieldwork takes. For traditional fieldwork within CMA, anthropologists spend time trying to participate and learn from the communities they work with, acting as learners and participators. Anthropologists working within CBPR approaches want community members to be collaborators, learning how to conduct investigative work and participating in research-as-culture (Cartwright \& Schow, 2016). Given the differences in the roles of community members and researchers between traditional fieldwork and CBPR research, this results in fundamentally different research designs, analyses, and outcomes as well.

Thinking of CBPR approaches as being complementary to traditional anthropological methods does a tremendous disservice to the "transformative logic" of CBPR (Watson, 2019, p. 23). CBPR approaches to medical anthropology research mean that the very process of fieldwork itself is subverted. Through "pursuing research within the context of action," a research project's methodologies and fieldwork will change, "most often in non-linear and unexpected ways, as much as the situation at hand" (Watson, 2019, p. 24). To use CBPR within medical anthropology is to use it as a theoretical lens to approach health research with a community. Working with Indigenous communities, this means centering the health concerns, priorities, and values that are brought forward by the community we intend to serve and embrace any changes in direction and interest along the way. 


\section{A way forward: Boundary work in medical anthropology}

IK understands environmental wellness as inclusive of the people that inhabit it and sees degradative processes as manifesting in community health and wellness as well (Arquette et al., 2014). Given that we come at the construction of a community health assessment with two culturally different understandings of health, it is useful to explore these differences together through boundary work. Within collaborative research, boundary work serves to support and further legitimize marginalized knowledge, such as IK of health (Zurba et al., 2019). Boundary work supports knowledge sharing across traditional boundaries and enhances the co-creation of knowledge within research partnerships. This work can help translate research outcomes into on-the-ground action as well, such as implementing programming and services. The partnership between Six Nations Health Services and McMaster operates within boundary work as a way of brokering interactions between these knowledge systems that may not have worked in shared spaces prior. As stated earlier, the research process is just as important as the final products of collaborative partnerships. However, to our knowledge, these concepts have not been applied within anthropological frameworks.

By using CBPR and boundary approaches within medical anthropology, it shifts the very nature and shape of how this research is carried out. While our health research is informed by our approaches to health as medical anthropologists, it mainly operates by listening to how Six Nations stakeholders wish to conduct the research and assess their own community health status. Given the history of mistrust and abuse between anthropologists and Indigenous communities in the past, framing the discussions we had leading up to and during the cocreation of a health assessment is a useful exercise to better understand the nuanced power dynamics within our research partnership and work towards creating more equitable and culturally centered health knowledge together.

\section{Creating safe health dialogues through boundary objects}

Boundary objects are often simple to understand across different members of a research collaboration. They are also structured to work at the margins of communities in order to enhance communication and reach across these boundaries to those with differing perspectives (Sapsed \& Salter, 2004). The success of the boundary object is not so much in its ability to bring consensus within a research community of practice, but in its effectiveness to create a space for discussion (Star, 2010). Through the three versions of the health survey over several years, many diverse perspectives and stakeholders were involved in conversations that contributed to the shape the survey took. More importantly, having a tangible document as a foundation for conversation allowed relationships to be built, and for them to grow and expand as trust and rapport was developed, and community concerns and needs shifted. With the history of unethical health research practiced on and not with Indigenous Peoples in Canada, having a boundary object helped to discuss the impacts and ripple effects of previous harm and dishonesty. Importantly, this allowed conversations to de-centre settler colonial perspectives and needs in favour of the concerns and priorities of Six Nations Health Services and community stakeholders on the project.

Engaged Scholar Journal: Community-Engaged Research, Teaching, and Learning 
Zurba and colleagues (2019) argue that it is important to reflect on how the boundary object facilitates boundary work for those working within a research collaboration, but also to assess how to use a boundary object to communicate outwardly. In our case, when we reflect on the community health assessment tool as a boundary object, it created a dialogical space between Indigenous and non-Indigenous research collaborators during its co-development. During the time in which community members were recruited and the household health and water use survey was administered, it operated as a communicative foundation with Six Nations community members. As community work continues to expand and results of preliminary research are shared, the survey will still serve as a boundary object to converse with community members.

\section{Challenges and barriers to co-creation}

As co-creation is a process involving multiple voices and perspectives, we wanted to present a brief discussion of the challenges and struggles we faced, as these are a realistic component of the research process. There are several instances where community leaders and partners have been over-worked within Six Nations, and our research project was not a priority, or leaves of absence were taken in response to emerging health and wellness concerns. There are the practical issues of finances, multiple jobs, or being spread too thin as well. These are elements that are difficult to navigate from an institutional perspective for community collaborators as well.

As Ball (2014) points out, "in the bureaucracy of a postsecondary institution, the policies, procedures, and timing that govern matters such as travel advances, expense claim reimbursements, payroll timesheets, cheque disbursements, and food purchases can seem labyrinthine and protracted, even to the most conditioned employees" (p. 35). These slowmoving practical matters were particularly challenging for community members who worked as RAs, where there were bureaucratic delays or policies around processing their wages that were frustrating, particularly for those balancing multiple other jobs and roles in the community. At times this led to departure, with new community members joining the team. This starts the process of relationship and trust-building again, and also means providing more time and space for these newer members to catch up to the speed of the project.

It certainly takes time to build relationships, which is a crucial way of ensuring a more respectful and equitable working partnership. For the health team, establishing relationships with the community navigators who lead and suggest who to reach out to within Six Nations for participation is important. Understanding each other's work ecologies and limitations (particularly as a graduate student researcher working with a community RA who holds multiple roles within both community and university) helps lay a working relationship foundation. And humour, above all, remains a good way of working through challenges and building relationships that will last beyond funding and research periods. 


\section{Institutional Barriers}

Within this research project, McMaster and Six Nations collaborators moved in two different ways, similar to the Two Row Wampum. The university as an institution has elaborate selfregulating structures and is slow to change. On the community side there are more fluid movements: leadership, circumstances, goals, and needs can and have changed within shorter periods of time. Singular community events can lead to large changes to the research process and eventual outcomes and dissemination, which means as academic researchers it is important to stay open and flexible, on a journey of discovery rather than being determined to meet specific and timely outcomes. There also feels, at times, a pressure to have immediate outcomes from research that will lead to immediate social changes, rather than accepting that the tools and knowledge that come from this co-creation will take time and may be more ambiguous throughout the process than expected.

The McMaster research team itself has a wide array of knowledge, expertise, and backgrounds, so it can be difficult sometimes to harmonize our work or work at similar speeds. For example, the time-sensitive biological sampling tests of tap and well-water by the ecosystem health team were difficult to perform at the same time as a household visit to do the water use and household health survey. The water samples needed to be back to the McMaster lab within a short time frame, and household visits for the surveys took a much longer time, averaging an hour per home visit. When we made singular trips to a household, those who were able to work more quickly (testing tap water would take 15 minutes per home) at times felt frustrated when the conversations stemming from the health survey made for 45 minutes to hour-long visits per house. Navigating these details and how to create work that is respectful of participants' time as much as respectful of each other's time was a challenge and one that we continue to reassess as we progress with the research.

Within this ambiguity also lies important considerations for academic researchers interested in engaging in this research. Co-creation of knowledge means that collaborators need to be comfortable with high levels of ambiguity and rapid (or punctuated) shifts in needs and directions as led by the community. For more novice researchers such as graduate students, this can be a difficult (albeit fruitful) learning experience to develop more adaptable ways of understanding emergent details and directions while maintaining academic and degree requirements. Guidance from community navigators and senior scholars is quite useful in these instances to help students remain on track, particularly from Indigenous researchers, as they are more experienced working within and between two worlds that may sometimes conflict with one other.

\section{Future Directions}

This paper reflects on the process of relationship building and co-developing tools and knowledge, and the dissemination process has not been discussed. Sharing knowledge and disseminating tools is itself a huge effort, in part because of the different ways that we can share the information and knowledge that comes from these health assessments for different audiences. We plan to share this knowledge as stories (digital and oral), as toolkits, and in ways 
that are useful for Six Nations Health Services to build increasingly more autonomous and resilience programs and policies to prevent illness and promote cultural and physical healing. In ways, the sharing of this knowledge will lead to more partnerships and mobilization of community and global Indigenous collaborations. Already, we are seeing the project grow with more moving parts and expand into important new territories of knowledge and needs as we begin to share findings with the community and expand our networks in varied ways.

We believe this paper contributes to the work of decolonizing medical anthropology by demonstrating how the co-production of a boundary object (through the example of health surveys) assists in bridging cultural and social boundaries. Most importantly, the discussions (or boundary work) around the health survey over the past two years have been spaces of important and respectful dialogue around sensitive issues of community and personal health, historical and intergenerational trauma, water and environmental relationships, and spirituality. The tradition of anthropology, and within that, medical anthropology, has centered itself as "explaining, representing, and exploring the unfamiliar for over a century" (Cartwright \& Schow, 2016, p. 137). If we are to continue exploring the unfamiliar, it is time for us to explore how we can build reciprocal, respectful relationships with the communities we work with, and explore the unfamiliarity of challenging conventional research structures and expectations.

It is important to assess the capacity for co-created research and work at the boundaries of cultural groups with a legacy of colonial power hierarchies. Ball (2014, p. 43) states that "In the expanded terrain of community-university engagement, risks are real and must, therefore, be carefully assessed. Before university-based and community partners venture onto the ice, they must be reasonably certain it is strong enough to withstand having holes drilled into it without risking lives." For our work on water quality and community health and resilience, this ice is much like the white rows of the Kaswentha, the river of life upon which our relationships are built and based in peace, strength, and a good mind. In times of challenges or emergent/ divergent research orientations, coming back to this foundation helps to revitalize our strengths working in harmony as western and Indigenous researchers.

\section{About the Authors}

Sarah Duignan (corresponding author) is a Ph.D. candidate in medical anthropology at McMaster University, Hamilton, ON. Her research interests are exploring the relationships between holistic health and water security using a biocultural approach. She is the coordinator of the community health assessment team for Co-Creation of Indigenous Water Quality Tools. Email: duignase@mcmaster.ca 
Dawn Martin-Hill (Mohawk Nation, Wolf Clan) is an associate professor with appointments in the Department of Anthropology and the Indigenous Studies Program at McMaster University. Her research is grounded in the principle that solution-based research in the area of Indigenous health must occur alongside building capacity for community collaborations. She is the Principal Investigator for two Global Water Futures projects, Co-Creation of Indigenous Water Quality Tools, and Ohneganos_-Water is Life.

Tina Moffat is an associate professor of anthropology at McMaster University. Her main area of interest is nutrition and food insecurity as it relates to the social, cultural, and physical environment. Her research perspectives are grounded in biocultural and political-economic approaches. She is the Co-Investigator for Co-Creation of Indigenous Water Quality Tools.

\section{References}

Airhihenbuwa, C., \& Libard, L. (2006). Eliminating health disparities in the African American population: the interface of culture, gender, and power. Health Education Research, 33, 488501.

Alvarez-Larrain, A., \& McCall, M.K. (2018). Participatory mapping and participatory GIS for historical and archaeological landscape studies: A critical review. Journal of Archaeological Method and Theory, 26, 643-678.

Arquette, M., Cole, M., \& Akwesasne Task Force on the Environment. (2004). Restoring Our Relationships for the Future. In Blaser, M., Feit, H.A., and McRae, G. (Eds.). In the Way of Development: Indigenous Peoples, Life Projects, and Globalization (pp. 332-350). London: Zed.

Atalay, S. (2007). Global application of Indigenous archaeology: Community-based participatory research in Turkey. Archaeologies, 3, 249-270.

Atalay, S. (2019). Can archaeology help decolonize the way institutions think? How communitybased research is transforming the archaeology training toolbox and helping to transform institutions. Archaeologies, 15, 514-535.

Baird, J., Carter, B., Cave, K., Dupont, D., General, P., King, C., Plummer, R., \& Varewyck, A. (2013). Gaining insights about Water: The value of surveys in First Nations communities to inform water governance. Indigenous Policy Journal, 23(4), 1-18.

Ball, J. (2014). On thin ice: Managing risks in community-university research projects. In Learning and Teaching Community-Based Research: Linking Pedagogy to Practice (pp. 332-350).

Blaser, M., Feit, H.A., \& McRae, G. (2004). In the Way of Development: Indigenous Peoples, Life Projects, and Globalization. London: Zed.

Bunch, M.J., Morrison, K.E., Parkes, M.W., \& Venema, H.D. (2011). Promoting health and wellbeing by managing for socio-ecological resilience: the potential for integrating ecohealth and water resources management approaches. Ecology and Society. 16(1), 6.

Cartwright, E., \& Schow, D. (2016). Anthropological perspective on participation in CBPR: Insights from the water project, Maras, Peru. Qualitative Health Research, 26(1), 136-140. 
Cash, D.W., \& Moser, S.C. (2000). Linking global and local scales: Designing dynamic assessment and management processes. Global Environmental Change, 10(2),109-120.

Chrisman, N.J., Strickland, C.J., Powell, K., Dick Squeochs, M., \& Yallup, M. (1999). Community partnership research with the Yakama Indian Nation. Human Organization, 58, 134-141.

Cochran, P.A., Marshall, C.A., Garcia-Downing, C., Kendall, E., Cook, D., McCubbin, L., Gover, R.M.S. (2008). Indigenous ways of knowing: Implications for participatory research and community. American Journal of Public Health, 98(1), 22-27.

Co-Creation of Indigenous Water Quality Tools Report (2019). CCIWQT Community Handout Report. Retrieved from https://static1.squarespace.com/static/5a0cddae51a584d71fb23968/ t/5cc1cd079140b7386606f983/1556204837312/CCIWQT+Update+-+April+2019.pdf

Constitution of Canada (1982). Retrieved from https://laws-lois.justice.gc.ca/eng/const/page-1.html

Coombes, B., Johnson, J.T., \& Howitt, R. (2012). Indigenous geographies I: Mere resource conflicts? The complexities in Indigenous land and environmental claims. Progress in Human Geography, 36(6), 810-821.

Daes, E. I. (1994). UN Sub-commission on the promotion and protection of human rights, Protection of the heritage of Indigenous people: preliminary report of the Special Rapporteur, EricaIrene Daes, submitted in conformity with Sub-Commission resolution 1993/44 and decision 1994/105 of the Commission on Human Rights. 8 July 1994. Retrieved from https:/ /www.refworld.org/ $\mathrm{docid} / 3 \mathrm{~b} 00 \mathrm{f} 25810 . \mathrm{html}$

Dignan M., Jones, K., Burhansstipanov, L., and Michalek, A.M. (2014). Evaluation lessons learned from implementing CBPR in Native American communities. Journal of Cancer Education, 29, 412-413.

Donatuto, J., Grossman, E.E., Konovsky, J., Grossman, S., \& Campbell, L.W. (2014). Indigenous community health and climate change: integrating biophysical and social science indicators. Coastal Management, 42(4), 355-373.

Drawson, A., Toombs, E., and Mushquash, C. (2017). Indigenous research methods: A systematic review. The International Indigenous Policy Journal, 8(2).

First Nations Information Governance Centre (FNIGC). (2014). Ownership, control, access, and possession (OCAP): The path to First Nations information governance. May 2014, Ottawa. Retrieved from https://fnigc.ca/sites/default/files/docs/ocap_path_to_fn_information_ governance_en_final.pdf

Garwick, A.W., \& Auger, S. (2003). Participatory action research: The Indian family stories project. Nursing Outlook, 51, 261-266.

Global Water Futures (2020). About Us. Retrieved from https://gwf.usask.ca/about-contact/aboutus.php

Gonzalelz, S.L., Kretzler, I., \& Edwards, B. (2018). Imagining Indigenous and archaeological futures: Building capacity with the Confederated Tribes of Grand Ronde. Archaeologies, 14, 15-114.

Gordon, K., Lickers Xavier, A., \& Tait Neufeld, H. (2018). Healthy Roots: Building capacity through shared stories rooted in Haudenosaunee knowledge to promote Indigenous foodways and well-being. Canadian Food Studies, 5(2), 180-195.

Hallenbeck, J. (2015). Returning to the water to enact a treaty relationship: the Two Row Wampum Renewal Campaign. Settler Colonial Studies, 5(4), 350-362.

Haudenosaunee Confederacy. (2019). The League of Nations. Retrieved from https://www. haudenosauneeconfederacy.com/the-league-of-nations/ 
Haudenosaunee Environmental Task Force (1992). Words That Come Before All Else: Environmental Philosophies of the Haudenosaunee. Akwesasane: North American Travelling College.

Hill, S.M. (2017). The Clay We Are Made Of: Haudenosaunee Land Tenure on the Grand River. Winnipeg: University of Manitoba.

Hollowell, J., \& Nicholas, G. (2009). Using ethnographic methods to articulate community-based conceptions of cultural heritage management. Public Archaeology: Archaeological Ethnographies, $8(2-3), 141-160$.

Hoover, E. (2017). The River Is in Us: Fighting Toxics in a Mobawk Community. Minneapolis: University of Minnesota.

Indian and Northern Affairs Canada. (2002). Words first: An evolving terminology relating to Aboriginal peoples in Canada. Retrieved from www.publications.gc.collections/Collection/ R2-236-2002E.pdf

Indigenous Services Canada (2019). Ending long-term drinking water advisories. Retrieved from https://www.sac-isc.gc.ca/eng/1506514143353/1533317130660

Jackson, P., \& Neely, AH. (2015). Triangulating health: Toward a practice of a political ecology of health. Progress in Human Geography, 39(1), 47-64.

Jessee, N., Collum, K.K., \& Schulterbrandt Gragg, R.D. (2015). Community-Based Participatory Research: Challenging the "Lone Ethnographer" Anthropology in the Community and the Classroom. Practicing Anthropology, 37(4), 9-13.

Kealiliikanakaoleohaililani, K. \& Giardini, C.P. (2016). Embracing the sacred: An Indigenous framework for tomorrow's sustainability science. Sustainability Science, 11, 57-67.

King, B. (2010). Political ecologies of health. Progress in Human Geography, 34, 38-55.

King, J.T. (2007). Value of water and the meaning of water law for the Native Americans known as the Haudenosaunee. Cornell Journal of Law and Public Policy, 16, 452.

Maclean, K., \& Bana Yarralji Bubu Inc. (2015). Crossing cultural boundaries: Integrating Indigenous water knowledge into water governance through co-research in the Queensland Wet Tropics, Australia. Geoforum, 59, 142-152.

MacMynowski, D.P. (2007). Pausing at the brink of interdisciplinarity: Power and knowledge at the meeting of social and biophysical science. Ecology and Society 12(1), Art. 20.

Marks, J. (2012). Why be against Darwin? Creationism, racism, and the roots of anthropology. Yearbook of Physical Anthropology, 55, 94-104.

Martin-Hill, D. (2009). Traditional medicine and restoration of wellness strategies. International Journal of Indigenous Health, 5(1), 26-42.

Mayer, JD. (1996). The political ecology of disease as one new focus for medical geography. Progress in Human Geography, 20(4), 441-456.

McGregor, D. (2008). Linking traditional ecological knowledge and western science: Aboriginal perspectives from the 2000 State of the Lakes Ecosystem conference. The Canadian Journal of Native Studies, 28(1), 139-158.

McGregor, D. (2012). Traditional knowledge: Considerations for protecting water in Ontario. The International Indigenous Policy Journal, 3(3), 1-21.

Monture, R. (2014). We Share Our Matters: Two Centuries of Writing and Resistence at Six Nations of the Grand River. Minneapolis: University of Minnesota.

Neegan Burnside Engineering and Environmental Ltd. (2005). Six Nations of the Grand River Hydroecological Study. Ohsweken, ON: Six Nations Council. 
Nelson, P.A. (2017). Indigenous archaeology at Tolay Lake: Responsive research and the empowered tribal management of a sacred landscape. (PhD dissertation, University of Berkeley). Escholarship.org

Newnham, E.C., Pincombe, J.I., \& McKellar, L.V. (2016). Critical medical anthropology in midwifery research: A framework for ethnographic analysis. Global Qualitative Nursing Research, 3, 1-6.

Porter, L., \& Barry, J. (2014). Bounded recognition: Urban planning and the textual mediation of Indigenous rights in Canada and Australia. Critical Policy Studies, 9(1), 22-40.

Richmond, C., Elliot, SJ, Matthews, R., \& Elliot, B. (2005). The political ecology of health: perceptions of environment, economy, health and wellbeing among 'Namgis First Nation. Health and Place, 11, 349-365.

Robinson, C.J. \& Wallington, T.J. (2012). Boundary work: Engaging knowledge systems in comanagement of feral animals on Indigenous lands. Ecology and Society, 17(2), Art. 16.

Sapsed, J., \& Salter, A. (2004). Postcards from the edge: Local communities, global programs and boundary objects. Organizational Studies, 25, 1515-1534.

Schneider, L. (2013). 'There's something in the water': Salmon runs and settler Colonialism on the Columbia River. American Indian Culture and Research Journal, 37(2), 150.

Sheehan, M., Burke, B., \& Slack, J. (2007). Graduate Education Grounded in Community-Based Participatory Research. Practicing Anthropology, 29(3), 18-21.

Shimo, A. (2018). While Nestle extracts millions of litres from their land, residents have no drinking water. The Guardian. Retrieved from https://www.theguardian.com/global/2018/oct/04/ ontario-six-nations-nestle-running-water?CMP=share_btn_fb\&page=with\%3Aimg-6\#img-6

Smedley, A., \& Smedley, B.D. (2005). Race as biology is fiction, Racism as social problem is real: Anthropological and historical perspectives on the social construction of race. American Psychologist, 60(1), 16-26.

Star, S.L. (2010). This is not a boundary object: Reflections on the origin of the concept. Science, Technology and Human Values, 35(5), 601-617.

Strickland, C. (2006). Challenges in community-based participatory research implementation: experiences in cancer prevention with Pacific Northwest Indian Tribes. Cancer Control, 13(3), 230-236.

Swain, H., Louttit, S., \& Hrudey, S. (2006). Report of the expert panel on safe drinking water for First Nations, Volume 1. Ottawa, ON: Minister of Indian Affairs and Northern Development.

TallBear, K. (2013). Native American DNA: Tribal Belonging and the False Promise of Genetic Science. Minneapolis: University of Minnesota.

Tobias, I. Richmond, C., \& Luginaah, I. (2013). Community-based participatory research (CBPR) with Indigenous communities: Producing respectful and reciprocal research. Journal of Empirical Research on Human Research Ethics, 8(2), 129-140.

Trembley, M.C., Martin, D.H., McComber, A.M., McGregor, A., and Macaulay, A.C. (2018). Understanding community-based participatory research through a social movement framework: a case study of the Kahnawake Schools Diabetes Prevention Project. BMC Public Health, $18,487$.

Tuhiwai Smith, L. (2008). Decolonizing Methodologies: Research and Indigenous Peoples. University of Otago. 
Wallerstein, N., Oetzel, J.G., Duran, B., Magarati, M., Pearson, C., Belone, L., Davis, J., DeWindt, L. Kastelic, S., Lucero, J., Ruddock, C., Sutter, E., \& Dutta, M.J. (2019). Culture-centeredness in community-based participatory research: contributions to health education invention research. Health Education Research, 34(4),372-388.

Watson, M.K. (2019). Pedagogy in action: Rethinking ethnographic training and practice in action anthropology. Anthropology in Action, 26(3), 23-34.

Wenger, E. (2000). Communities of practice: Learning as a social system. Systems Thinker, 9(5).

Zurba, M., \& Berkes, F. (2014). Caring or country through participatory art: Creating a boundary object for communicating Indigenous knowledge and values. Local Environment, 19(8), 821836.

Zurba, M., Maclean, K., Woodward, E., \& Islam, D. (2019). Amplifying Indigenous community participation in place-based research through boundary work. Progress in Human Geogrpaby, 43(6), 1020-1043.

Engaged Scholar Journal: Community-Engaged Research, Teaching, and Learning 